\title{
Changes in Dissociation Efficiency and Kinetics of Peptide lons Induced by Basic Residues and Their Mechanistic Implication
}

\author{
So Hee Yoon, ${ }^{1}$ Jeong Hee Moon, ${ }^{2}$ Myung Soo Kim ${ }^{1}$ \\ ${ }^{1}$ Department of Chemistry, Seoul National University, Seoul, Korea \\ ${ }^{2}$ Medical Proteomics Research Center, KRIBB, Daejeon, Korea
}

\begin{abstract}
With matrix-assisted laser desorption ionization (MALDI) time-of-flight (TOF) mass spectrometry, total abundance of product ions formed by dissociation inside (in-source decay, ISD) and outside (post-source decay, PSD) the source was measured for peptide ions $\left[Y_{5} X+\mathrm{H}\right]^{+},\left[X Y_{5}+\right.$ $\mathrm{H}]^{+},\left[Y_{2} X Y_{3}+\mathrm{H}\right]^{+}$, and $\left[X Y_{4} X+\mathrm{H}\right]^{+}(X=$ tyrosine $(Y)$, histidine $(H)$, lysine $(K)$, and arginine $(R)$ with $\mathrm{H}$ for the ionizing proton). $\alpha$-Cyano-4-hydroxycinammic acid was used as matrix. Product abundance became smaller in the presence of basic residues $(H, K$, and $R)$, in the order $Y>H \approx$ $K>R$. In particular, product abundances in ISD of peptide ions with $R$ were smaller than those with $H$ or $K$ by an order of magnitude, which, in turn, were smaller than that for $\left[Y_{6}+\mathrm{H}\right]^{+}$by an order of magnitude. Product abundance was affected by the most basic residue when more than one basic residue was present. A kinetic explanation for the data was attempted under the assumption of quasi-thermal equilibrium for peptide ions in MALDI plume which undergoes expansion cooling. Dramatic disparity in product abundance was found to arise from small difference in critical energy and entropy. Results indicate similar transition structures regardless of basic residues present, where the ionizing proton keeps interacting with a basic site. Further implication of the results on the dissociation mechanism along $b-y$ channels is discussed.
\end{abstract}

Key words: MALDI, In-source decay, Post-source decay, Peptide dissociation, Basic residue effect, Dissociation efficiency, Dissociation kinetics and mechanism

\section{Introduction}

$\mathrm{D}$ issociation mechanism of peptide ions is of current interest [1-6] in relation to protein sequencing by tandem mass spectrometry. Major product ions, $b$ and $y$, are thought to form via charge-directed cleavage of amide bonds occurring after the migration of a proton to an amide backbone. The reaction will be less efficient in the presence of a basic residue

Electronic supplementary material The online version of this article (doi:10.1007/s13361-010-0043-2) contains supplementary material, which is available to authorized users.

Correspondence to: Myung Soo Kim; e-mail: myungsoo@snu.ac.kr (histidine $(H)$, lysine $(K)$, and arginine $(R)$ ) because proton migration will be more difficult. To our knowledge, however, there has been no systematic study of the influence of basic residues on total dissociation efficiency.

Recently [7, 8], we measured product ion yields in postsource decay (PSD) and time-resolved photodissociation of peptide ions with matrix-assisted laser desorption ionization (MALDI) time-of-flight (TOF) mass spectrometry and determined the dissociation critical energy $\left(E_{0}\right)$ and entropy $\left(\Delta S^{\ddagger}\right)$ through analysis with Rice-Ramsperger-KasselMarcus (RRKM) theory [9, 10]. One rate constant was assigned to the cleavage of an amide bond because the bifurcation to $b$ and $y$ was thought to occur after the ratedetermining step $[3,6,11]$. To estimate the total rate constant 
for competitive cleavage of several amide bonds, the rate constant for a typical $b-y$ channel was multiplied by the number of amide bonds. Peptide ions containing arginine were difficult to study because charge-remote fragmentation [5] also occurred.

The kinetic analysis also provided information on the peptide ion internal energy in the form of effective temperature; $400-470 \mathrm{~K}$ found for $\left[Y_{6}+\mathrm{H}\right]^{+}$-italic characters will be used for amino acid residues in peptides-was close to the result determined by Mowry and Johnston [12] through photoionization of neutrals desorbed by MALDI. However, it was significantly lower than 736-960 K estimated by Yergey et al. [13] from in-source decay (ISD) yield or $>800 \mathrm{~K}$ surface temperature determined by Zenobi et al. [14] through detection of blackbody radiation. To find an explanation for the rather low temperature determined by our tandem mass spectrometric method, we investigated ISD of $\left[Y_{6}+\mathrm{H}\right]^{+}$and found that it occurred efficiently but subsided rapidly (within $150 \mathrm{ns)} \mathrm{[15].} \mathrm{A} \mathrm{simple} \mathrm{estimation}$ utilizing the yield and the lifetime of ISD showed that it should have been impossible to detect the peptide ion signal if its temperature in 'early' MALDI plume had been maintained. This dictated rapid expansion cooling of the peptide ion [16], which occurs in adiabatic expansion of high density gas to vacuum. Assuming $50 \mathrm{~ns}$ lifetime for ISD, 800-900 K was estimated as the temperature in 'early' plume. The temperature must have dropped to $400-470 \mathrm{~K}$ in 'late' plume, as found in our previous kinetic study, by expansion cooling. The result was in agreement not only with previous temperature estimations but also with the finding in a recent computational study [17].

Subsequently, we extended ISD study to peptide ions containing basic residues and observed dramatic decrease of product ion abundance in their presence. We realized that the method to estimate the temperature in early plume, when used in reverse, could determine the dissociation kinetics. Product ion abundances in ISD and PSD of peptide ions containing basic residues and differences in dissociation kinetics $\left(E_{0}\right.$ and $\left.\Delta S^{\ddagger}\right)$ caused by such residues are reported in this paper. Implication of the results for the dissociation mechanism will also be discussed.

\section{Experimental}

A schematic drawing of the homebuilt tandem TOF instrument [18] used in this work is shown in Figure 1. The instrument consists of a MALDI source with delayed

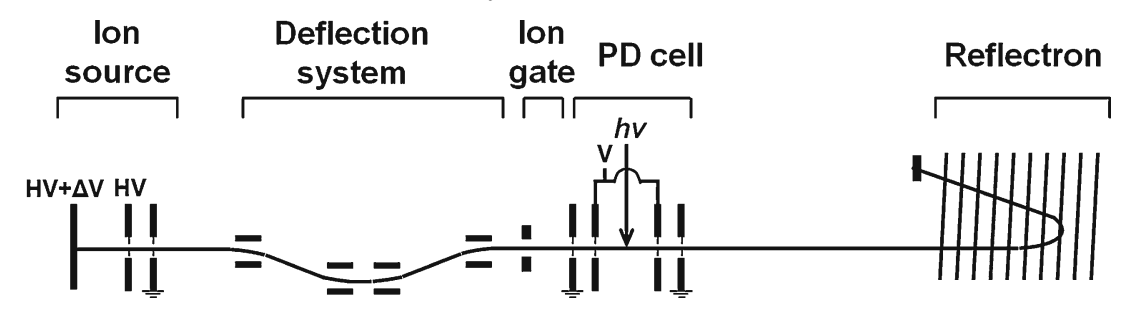

Figure 1. A schematic drawing of the homebuilt MALDI-tandem TOF used in this work. A deflection system consisting of four deflectors is installed in front of the ion gate to eliminate PSD product ions formed between the ion source and the ion gate. Details of the instrument and its operation are described in the Experimental section and in references [18] and [19] extraction, a linear TOF analyzer to separate ions generated by MALDI, an ion gate, a PD cell (not used in this work), and a second-stage TOF analyzer equipped with a reflectron. Due to a deflection system [19] installed in the linear TOF region, only product ions formed in the region between the exit of this system and the reflectron entrance are detected as PSD. Flight time spent by a precursor ion in this region is $16.5 \%(1 / 6)$ of its total flight time to the detector. $337 \mathrm{~nm}$ output from a nitrogen laser (MNL100; Lasertechnik Berlin, Berlin, Germany) focused by $\mathrm{f}=250 \mathrm{~mm}$ lens was used for MALDI. $20 \mathrm{kV}$ DC and $1.5 \mathrm{kV}$ AC pulse were used in the source and the final electrode of the reflectron was kept at $25 \mathrm{kV}$.

$\alpha$-Cyano-4-hydroxycinammic acid (CHCA) was used as matrix. $1.4 \mu \mathrm{J} /$ pulse of MALDI laser was used throughout the measurement, which is around two times the threshold value. Each spectrum was averaged over 3000 MALDI shots. Five or more duplicate measurements were made for different samples in different days.

\section{Reflectron and Peaks Appearing in a MALDI Spectrum}

The potential inside the reflectron equipped in the apparatus has both linear and quadratic components [18]. This allows unit mass resolution at low $\mathrm{m} / \mathrm{z}$ even when the reflectron voltage is not stepped. The only operational difference between MALDI and PSD modes is the activation of the ion gate in PSD for precursor ion selection. Hence, PSD product ions, either from a peptide ion or from its ISD products, appear with good resolution in MALDI spectrum. That is, $\mathrm{MS}^{1}$ (a peptide ion), $\mathrm{MS}^{2}$ (its ISD and PSD products), and $\mathrm{MS}^{3}$ (PSD of ISD products) data are available from a high resolution MALDI spectrum. In this work, the abundances of product ions formed by ISD and PSD were measured from MALDI spectra to assure the same experimental condition for their measurement.

\section{Ion Intensity Measurement}

The method to calibrate the gain of the MCP detector was reported previously [7]. Ion intensity was measured in timecoordinate (TOF) spectrum, not in mass spectrum, by integrating ion current for each peak. Care was taken to avoid detector saturation even for the strongest peak in a 
spectrum. Contributions from higher mass isotopic peaks were included in ion intensity.

\section{Samples}

All the peptides were purchased from Peptron (Daejeon, Korea). CHCA and other chemicals were purchased from Sigma (St. Louis, MO, USA). A matrix solution prepared with $1: 1$ acetonitrile $/ 0.1 \%$ trifluoroacetic acid was mixed with aqueous solution of peptides. Matrix-to-analyte molar ratio was 1000:1.

\section{Results}

\section{Spectra}

CHCA-MALDI and PSD spectra for $Y_{5} X(X=Y, H, K$, and $R$ ) are shown in Figures 2 and 3, respectively. Spectra for the other peptide ions studied in this work are shown in Supplementary Material. Each spectrum was normalized to the peptide ion abundance. Product ions appearing in PSD spectra are marked in the figures, which are mostly $a, b, y$, and immonium ions such as $\mathrm{Y}$. In addition, $\left[\mathrm{M}+\mathrm{H}-\mathrm{NH}_{3}\right]^{+}$, $a-\mathrm{NH}_{3}, b-\mathrm{NH}_{3}$, and $y-\mathrm{NH}_{3}$ appear in PSD spectra for peptide ions containing arginine. Similar product ions are formed by ISD as marked in MALDI spectra. Matrix-related peaks and PSD peaks from peptide ions are also marked. $v$-Type ions appear in MALDI spectra of peptides containing arginine, which are produced by charge-remote fragmentation [5].

\section{Product Ion Abundances and Survival Probabilities}

Sum of product ion abundances in PSD divided by the peptide ion abundance will be called $\mathrm{Y}_{\mathrm{PSD}}$. In the present instrument, a PSD spectrum records product ions formed in the region between the exit of the deflection system and the reflectron entrance. That is, product ions formed by postsource dissociation occurring outside of this region are not detected. Since the flight time spent by a precursor ion in this

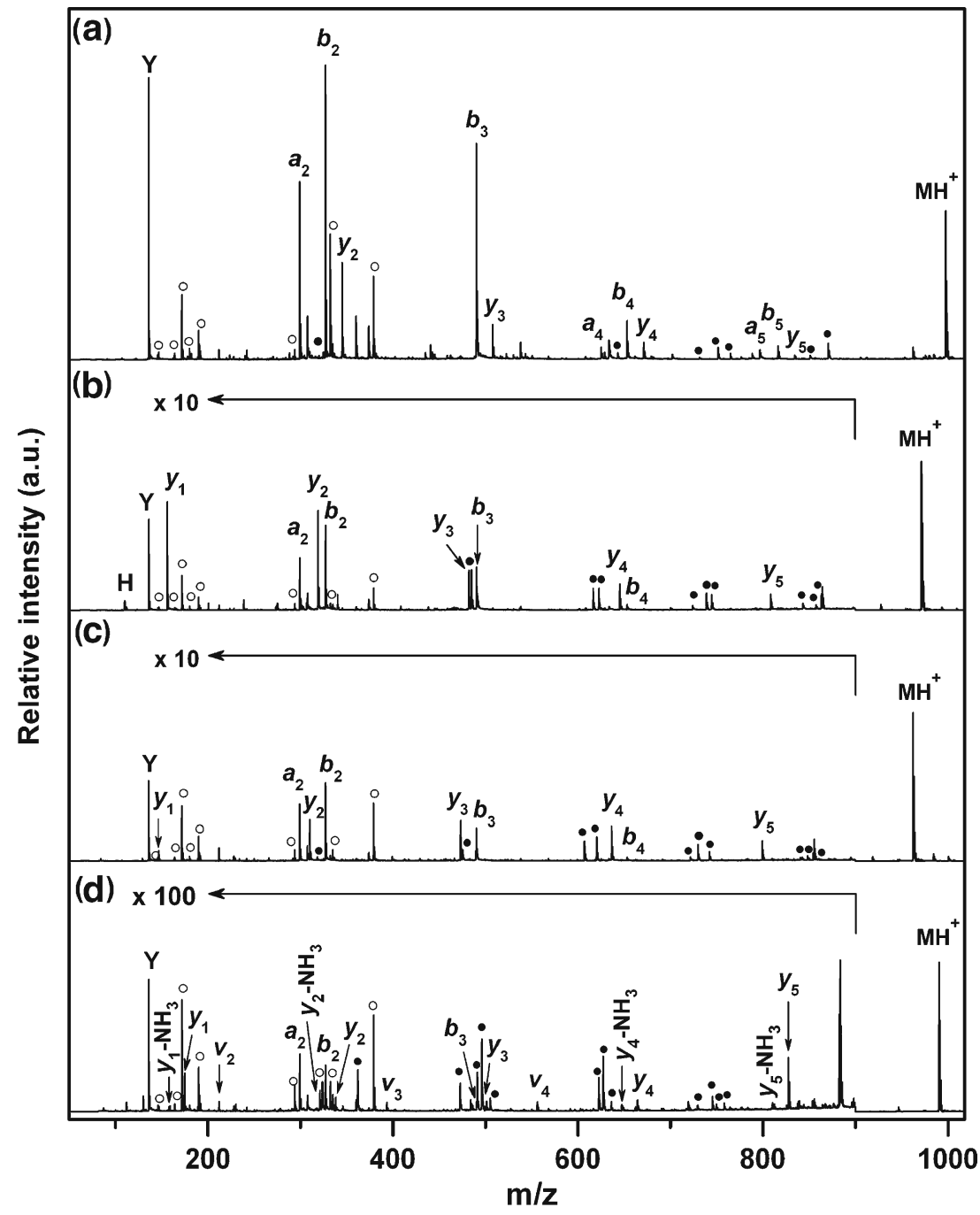

Figure 2. MALDI spectra of (a) $Y_{6}$, (b) $Y_{5} H$, (c) $Y_{5} K$, and (d) $Y_{5} R$. Each spectrum was normalized to the peptide ion abundance. ISD product ions are assigned. Peaks due to matrix $(\circ)$ and PSD of the peptide ions $(\bullet)$ are marked 


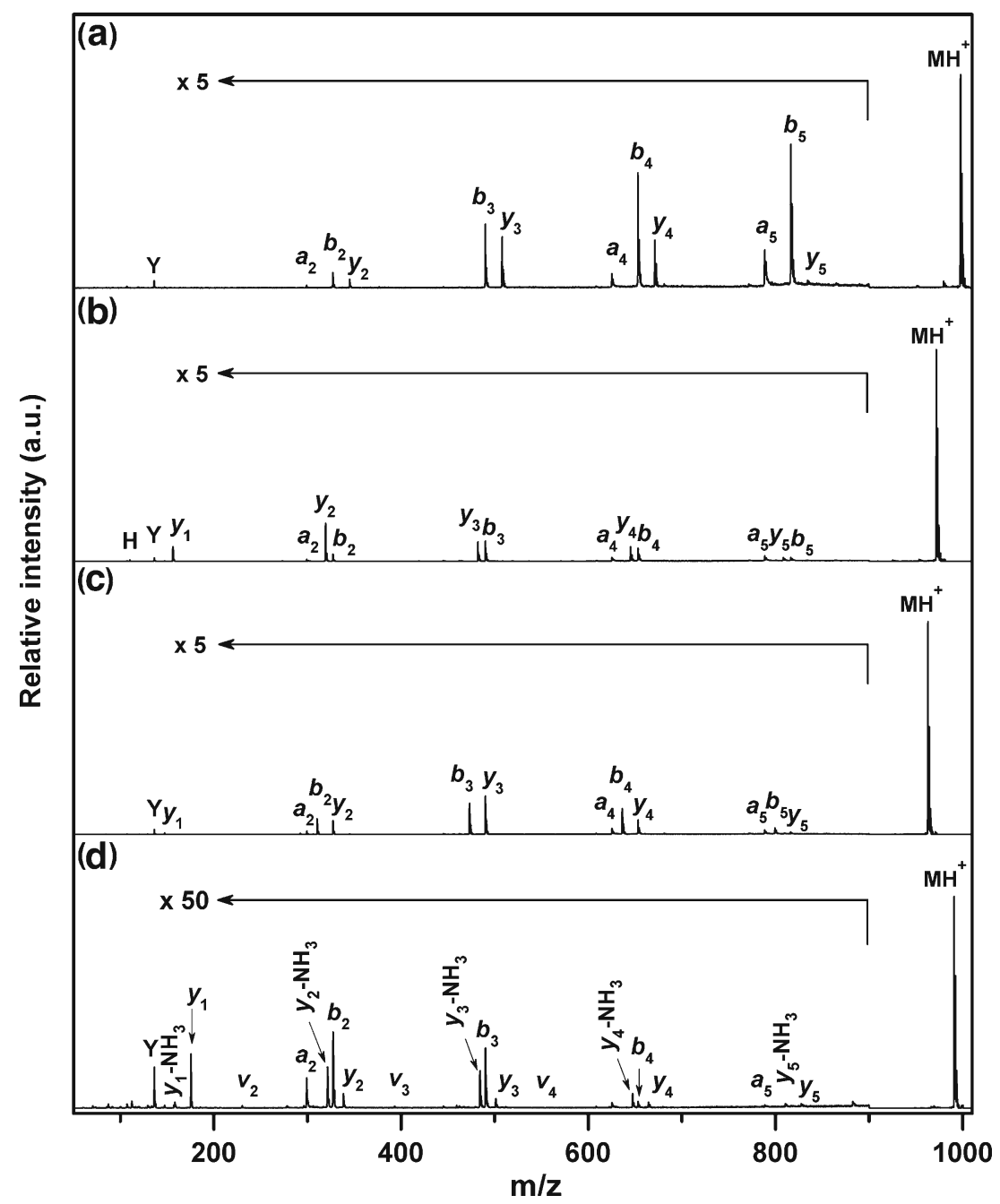

Figure 3. PSD spectra of (a) $\left[Y_{6}+H\right]^{+}$, (b) $\left[Y_{5} H+H\right]^{+}$, (c) $\left[Y_{5} K+H\right]^{+}$, and (d) $\left[Y_{5} R+H\right]^{+}$. Each spectrum was normalized to the peptide ion abundance

region is $16.5 \%(1 / 6)$ of its total flight time to the detector, the total relative abundance for post-source dissociation ( $\mathrm{Y}_{\text {total PSD }}$ ) was estimated as $6 \times \mathrm{Y}_{\mathrm{PSD}}$ (errors due to this approximation will be checked later). Then, the probability $\left(\mathrm{S}_{\text {post }}\right)$ for a peptide ion emerging from the ion source to survive post-source dissociation becomes $1 /\left(1+\mathrm{Y}_{\text {total } \mathrm{PSD}}\right)$. The survival probability in the ion source $\left(\mathrm{S}_{\mathrm{in}}\right)$ was estimated as follows. The abundance of each ISD product ion was multiplied by its $\left(1+\mathrm{Y}_{\text {total PSD }}\right)$ to estimate the abundance at the source exit, i.e., prior to postsource dissociation. Similar correction was made for the peptide ion. The sum of the corrected abundances for ISD product ions divided by that of the peptide ion will be called $\mathrm{Y}_{\text {total ISD. Then, }}$ $\mathrm{S}_{\text {in }}$ becomes $1 /\left(1+\mathrm{Y}_{\text {total ISD }}\right) \cdot\left[\mathrm{M}+\mathrm{H}-\mathrm{NH}_{3}\right]^{+}$and $v$ were not included in the calculation because we were interested in $b-y$ channels. $a-\mathrm{NH}_{3}, b-\mathrm{NH}_{3}$, and $y-\mathrm{NH}_{3}$ ions were included even though some of them may have been formed from $[\mathrm{M}+\mathrm{H}-$ $\left.\mathrm{NH}_{3}\right]^{+}$. Their inclusion caused minor variation in final results. $\mathrm{Y}_{\text {total ISD }}, \mathrm{Y}_{\text {total PSD }}, \mathrm{S}_{\mathrm{in}}$, and $\mathrm{S}_{\text {post }}$ for the peptide ions studied are listed in Table 1 together with those for $\left[Y_{6}+\mathrm{H}\right]^{+}$.
Both $Y_{\text {total ISD }}$ and $Y_{\text {total PSD }}$ data form three groups with decreasing order $\left\{\right.$ no basic residue, i.e., $\left.\left[Y_{6}+\mathrm{H}\right]^{+}\right\}>$peptide ions with $H$ or $K\}>$ peptide ions with $R$ \} as expected from the basicity order $Y<H \approx K<R$. The influence of basic residues

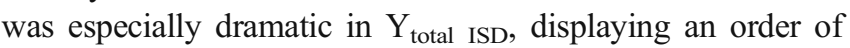
magnitude difference between the first and second groups and also between the second and third groups. Grouping held regardless of the position and number of basic residues. From the data for $\left[\mathrm{HY}_{4} \mathrm{R}+\mathrm{H}\right]^{+}$, the most basic site in a peptide ion seems to govern its dissociation efficiency. Even though grouping also held for survival probabilities, difference was less dramatic, indicating that the dramatic disparity in product ion abundance was caused by small difference in dissociation kinetics $\left(E_{0}\right.$ and $\left.\Delta S^{\dagger}\right)$.

\section{Kinetic Analysis}

The critical energy $\left(E_{0}\right)$ and entropy $\left(\Delta S^{\ddagger}\right)$ for the cleavage of a typical amide bond in $\left[Y_{6}+\mathrm{H}\right]^{+}$determined previously 
Table 1. Product ion abundances, survival probabilities, $E_{0}$ (in eV), and $\Delta S^{\ddagger}$ (in eu, $\left.1 \mathrm{eu}=4.184 \mathrm{JK}^{-1} \mathrm{~mol}^{-1}\right)^{\mathrm{a}}$

\begin{tabular}{|c|c|c|c|c|c|c|}
\hline & $Y_{\text {total ISD }}$ & $\mathrm{Y}_{\text {total PSD }}$ & $\mathrm{S}_{\text {in }}$ & $\mathrm{S}_{\text {post }}$ & $E_{0}$ & $\Delta S^{\ddagger}$ \\
\hline$\left[Y_{6}+\mathrm{H}\right]^{+}$ & 4.05 & 5.06 & 0.198 & 0.165 & 0.600 & -28.4 \\
\hline$\left[Y_{5} H+\mathrm{H}\right]^{+}$ & $0.50 \pm 0.06$ & $1.73 \pm 0.22$ & $0.67 \pm 0.03$ & $0.37 \pm 0.03$ & $0.621 \pm 0.003$ & $-28.0 \pm 0.2$ \\
\hline$\left[H Y_{5}+\mathrm{H}\right]^{+}$ & $0.37 \pm 0.06$ & $2.59 \pm 0.63$ & $0.73 \pm 0.03$ & $0.28 \pm 0.05$ & $0.609 \pm 0.008$ & $-28.8 \pm 0.4$ \\
\hline$\left[Y_{2} H_{Y_{3}}+\mathrm{H}\right]^{+}$ & $0.65 \pm 0.07$ & $1.97 \pm 0.05$ & $0.61 \pm 0.03$ & $0.34 \pm 0.01$ & $0.617 \pm 0.001$ & $-28.1 \pm 0.1$ \\
\hline$\left[\mathrm{HY}_{4} H+\mathrm{H}\right]^{+}$ & $0.47 \pm 0.08$ & $1.17 \pm 0.13$ & $0.68 \pm 0.04$ & $0.46 \pm 0.03$ & $0.632 \pm 0.004$ & $-27.5 \pm 0.2$ \\
\hline$\left[Y_{5} K+\mathrm{H}\right]^{+}$ & $0.42 \pm 0.04$ & $1.29 \pm 0.10$ & $0.71 \pm 0.02$ & $0.44 \pm 0.02$ & $0.630 \pm 0.003$ & $-27.6 \pm 0.2$ \\
\hline$\left[K Y_{5}+\mathrm{H}\right]^{+}$ & $0.82 \pm 0.14$ & $1.86 \pm 0.13$ & $0.55 \pm 0.05$ & $0.35 \pm 0.02$ & $0.623 \pm 0.005$ & $-27.8 \pm 0.1$ \\
\hline$\left[Y_{2} K Y_{3}+\mathrm{H}\right]^{+}$ & $0.51 \pm 0.07$ & $1.92 \pm 0.45$ & $0.66 \pm 0.03$ & $0.34 \pm 0.05$ & $0.618 \pm 0.007$ & $-28.1 \pm 0.4$ \\
\hline$\left[K Y_{4} K+\mathrm{H}\right]^{+}$ & $0.49 \pm 0.06$ & $0.94 \pm 0.07$ & $0.67 \pm 0.03$ & $0.51 \pm 0.02$ & $0.639 \pm 0.003$ & $-27.1 \pm 0.2$ \\
\hline$\left[Y_{5} R+\mathrm{H}\right]^{+}$ & $0.047 \pm 0.011$ & $0.45 \pm 0.11$ & $0.96 \pm 0.01$ & $0.69 \pm 0.05$ & $0.660 \pm 0.007$ & $-27.2 \pm 0.3$ \\
\hline$\left[R Y_{5}+\mathrm{H}\right]^{+}$ & $0.063 \pm 0.042$ & $0.47 \pm 0.23$ & $0.94 \pm 0.04$ & $0.69 \pm 0.12$ & $0.661 \pm 0.017$ & $-27.6 \pm 0.6$ \\
\hline$\left[Y_{2} R Y_{3}+\mathrm{H}\right]^{+}$ & $0.024 \pm 0.005$ & $0.23 \pm 0.06$ & $0.98 \pm 0.01$ & $0.81 \pm 0.04$ & $0.678 \pm 0.008$ & $-26.6 \pm 0.3$ \\
\hline$\left[R Y_{4} R+\mathrm{H}\right]^{+}$ & $0.10 \pm 0.03$ & $0.52 \pm 0.13$ & $0.91 \pm 0.02$ & $0.66 \pm 0.06$ & $0.658 \pm 0.006$ & $-27.1 \pm 0.4$ \\
\hline$\left[\mathrm{HY}_{4} \mathrm{R}+\mathrm{H}\right]^{+}$ & $0.079 \pm 0.026$ & $0.44 \pm 0.10$ & $0.93 \pm 0.02$ & $0.69 \pm 0.03$ & $0.658 \pm 0.007$ & $-26.9 \pm 0.2$ \\
\hline
\end{tabular}

${ }^{\text {a }}$ Data for $\left[Y_{6}+\mathrm{H}\right]^{+}$used as benchmarks to find differences in $E_{0}$ and $\Delta S^{\sharp}$.

$[7,8]$ were $0.60 \mathrm{eV}$ and $-28.4 \mathrm{eu}\left(1 \mathrm{eu}=4.184 \mathrm{JK}^{-1} \mathrm{~mol}^{-1}\right)$, respectively. The total rate constant $\left(k_{\text {tot }}(E)\right)$ calculated with these parameters is shown in Figure 4a. In the ISD study of $\left[Y_{6}+\mathrm{H}\right]^{+}[15]$, the temperature in early plume was estimated by postulating $50 \mathrm{~ns}$ as the lifetime of ISD, or $1.4 \times 10^{7} \mathrm{~s}^{-1}$ in rate constant. The internal energy $(E)$ corresponding to this rate constant, $11.585 \mathrm{eV}$, was taken as the threshold energy for ISD and the early plume temperature was determined by equating the area below this threshold in the internal energy distribution with $\mathrm{S}_{\mathrm{in}}$. The same treatment of the data for $\left[Y_{6}\right.$ $+\mathrm{H}]^{+}$in Table 1 resulted in $881 \mathrm{~K}$ (versus $880 \mathrm{~K}$ reported previously [15]). We will further postulate $5.4 \times 10^{4} \mathrm{~s}^{-1}$ as the threshold rate constant for the post-source dissociation of $\left[Y_{6}+\mathrm{H}\right]^{+}$based on the average time for its occurrence. This results in $463 \mathrm{~K}$ (versus $469 \pm 22 \mathrm{~K}$ reported previously [8]) as the temperature in late plume. The internal energy distributions for $\left[Y_{6}+\mathrm{H}\right]^{+}$at 463 and $881 \mathrm{~K}$ are shown in Figure $4 \mathrm{~b}$. A peptide ion formed by processes such as proton transfer may be initially hotter than plume. However, the fact that it comprises a tiny fraction of plume and that it would suffer many collisions in high density plume suggest that its temperature will get close to that of plume and undergo efficient expansion cooling. Hence, the same temperature will be assumed for all the peptide ions studied (errors due to this assumption will be checked later). Taking 463 and $881 \mathrm{~K}$ as the temperatures in late and early plumes, respectively, means that $k_{\text {tot }}(E)$ for $\left[Y_{6}+\mathrm{H}\right]^{+}$, or its $E_{0}$ and $\Delta S^{\ddagger}$, is taken as the benchmark in studying the changes in dissociation kinetics caused by basic residues.

Kinetic analysis proceeded as follows: $1.4 \times 10^{7} \mathrm{~s}^{-1}$ was taken as the ISD threshold rate constant for all the peptide ions. The threshold rate constant for the post-source dissociation of each ion was a little different from that for $\left[Y_{6}+\mathrm{H}\right]^{+}$due to difference in flight time. Then, the ISD threshold energy, i.e., $E$ corresponding to $k_{\text {tot }}(E)=1.4 \times 10^{7} \mathrm{~s}^{-1}$, for each peptide ion was determined by equating the area below this energy in its internal energy distribution at $881 \mathrm{~K}$ with $\mathrm{S}_{\text {in }}$. This provided one point on the $E-k$ plane. Similar treatment of $\mathrm{S}_{\text {post }}$ provided another point. Finally, by finding $k_{\text {tot }}(E)$ passing through these two points with RRKM calculation, $E_{0}$ and $\Delta S^{\ddagger}$ were determined. Results are listed in Table 1 with random errors in five or more measurements.

Even though charge-remote fragmentation channels also operate in ISD of peptide ions containing arginine and generate product ions such as $v$, they were not included in the estimation of $\mathrm{S}_{\mathrm{in}}$. Kinetic analysis for $b-y$ channels with such $S_{\text {in }}$ is an excellent approximation when $S_{\text {in }}$ is close to 1 and the former channels are not dominant, as observed in this work. To check other systematic errors, we changed the threshold rate constants and the factor $(\times 6)$ used to estimate $Y_{\text {total }}$ PSD by $\pm 50 \%$ and found variations smaller than random errors in the final results. To estimate the systematic errors arising from the errors in $E_{0}$ and $\Delta S^{\ddagger}$ for $\left[Y_{6}+\mathrm{H}\right]^{+}$ used as benchmarks, we performed kinetic analysis using

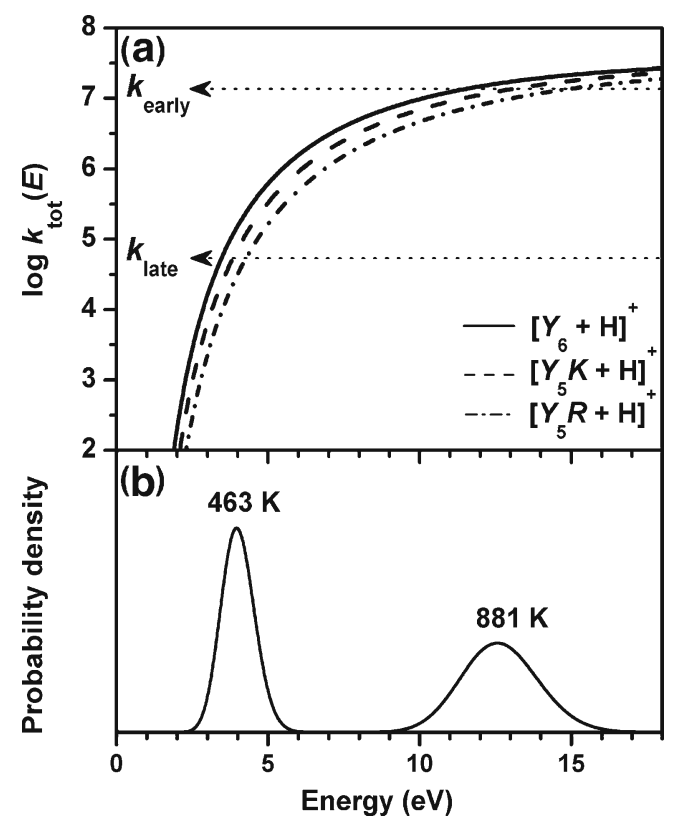

Figure 4. (a) $k_{\text {tot }}(E) s$ for $\left[Y_{6}+\mathrm{H}\right]^{+}(-),\left[Y_{5} K+H\right]^{+}(---)$, and $\left[Y_{5} R+H\right]^{+}(-\cdot-)$. Two threshold rate constants are marked. (b) Internal energy distributions for $\left[Y_{6}+\mathrm{H}\right]^{+}$at 463 and $881 \mathrm{~K}$ 
widely different values for these parameters, even if $k_{\mathrm{tot}}(E)$ thus obtained was completely inconsistent with our previous time-resolved photodissociation data. For example, when $E_{0}$ for $\left[Y_{6}+\mathrm{H}\right]^{+}$was raised from $0.60 \mathrm{eV}$ to $1.1 \mathrm{eV}, E_{0}$ for $\left[Y_{5} R\right.$ $+\mathrm{H}]^{+}$increased from $0.660 \mathrm{eV}$ to $1.168 \mathrm{eV}$, with the difference between $\left[Y_{6}+\mathrm{H}\right]^{+}$and $\left[Y_{5} R+\mathrm{H}\right]^{+}$changing from $0.060 \mathrm{eV}$ determined in this work to $0.068 \mathrm{eV}$. Changes were smaller for peptide ions containing $H$ or $K$. That is, the changes in $E_{0}$ and $\Delta S^{\ddagger}$ caused by basic residues determined in this work are probably meaningful even if the benchmark data are inaccurate. Finally, we checked the potential error arising from our assumption of the same temperature for different peptide ions as follows. The formation of $\left[Y_{5} R+\mathrm{H}\right]^{+}$ via proton transfer with a matrix-related ion might be more exothermic than that of $\left[Y_{6}+\mathrm{H}\right]^{+}$roughly by the difference in proton affinity $(P A)$ between $R$ and $Y$, which is $1.04 \mathrm{eV}$ [20]. $1.04 \mathrm{eV}$ higher internal energy for $\left[Y_{5} R+\mathrm{H}\right]^{+}$was equivalent to $43 \mathrm{~K}$ higher early plume temperature, which resulted in $0.004 \mathrm{eV}$ smaller $E_{0}$ and $0.7 \mathrm{eu}$ smaller $\Delta S^{\ddagger}$ than the original treatment. That is, temperatures used were not critical to the final results.

Even though product ion abundance was significantly affected by basic residues, their influence on dissociation kinetics, i.e., changes in $E_{0}$ and $\Delta S^{\sharp}$, was small-the fact that small changes in $E_{0}$ and $\Delta S^{\ddagger}$ cause significant change in $k(E)$ at large internal energy is well known in RRKM kinetics. Still, it is evident that basic residues affect dissociation kinetics mainly by increasing $E_{0}$, even though their influence on $\Delta S^{\star}$ can not be ignored. Considering random errors, their influence on $E_{0}$ seems to be similar regardless of their position inside a peptide ion. Concerning the influence of two basic residues, two different trends were observed. For peptide ions with $H$ or $K, E_{0}$ increased with an additional basic residue, while hardly any change occurred for peptide ions with $R$.

\section{Discussion}

According to proton affinities $(P A)$ for gas-phase amino acids in literature [20], $P A$ of $Y$ is smaller than those of $H, K$, and $R$ by $0.46,0.64$, and $1.04 \mathrm{eV}$, respectively. Taking $\left[Y_{5} H+\mathrm{H}\right]^{+},\left[Y_{5} K+\mathrm{H}\right]^{+}$, and $\left[Y_{5} R+\mathrm{H}\right]^{+}$as examples, their $E_{0}$ values determined in this work are larger than that for $\left[Y_{6}+\mathrm{H}\right]^{+}$by $0.021,0.030$, and $0.060 \mathrm{eV}$, respectively. That is, even though $E_{0}$ gets larger in the presence of a more basic residue, changes in $E_{0}$ are much smaller than those in $P A$. Let us suppose that the ionizing proton is initially at the Nterminus or at the side chain of a basic residue and that the transition structure (TS) for a $b-y$ channel is formed via complete migration of the proton to an amide backbone, as widely thought [1-3]. Then, one would expect that $P A$ change would be reflected in $E_{0}$ change to a larger extent than found. Hence, very small change in $E_{0}$ found is evidence that the ionizing proton does not completely migrate to an amide backbone, but keeps interacting with a basic site even in TS. This is also compatible with highly negative $\Delta S^{\sharp}$ found for all the peptide ions which suggests an entropy bottleneck as TS. TS in the formation of $b$ and $y$ via oxazolone pathway was found for small model peptide ions by quantum chemical calculation $[4,6,11]$. A modification of this structure, i.e., a proton-bound form in which the ionizing proton interacts both with a basic site and with an amide backbone, is shown in Figure 5 as a potential candidate for TS. As the basicity of the site interacting with the proton in TS increases, it will interact more with the proton and hence make the amide backbone less labile. This may be an explanation for larger $E_{0}$ in the presence of a more basic residue. Gas-phase basicities $(G B)$ for di- and tripeptides are similar regardless the position of basic residues [20]. This is compatible with our finding that the influence of basic residues is not quite site-specific.

$E_{0}$ for $\left[X Y_{4} X+\mathrm{H}\right]^{+}$was larger than those for its monobasic counterparts when $X$ was $H$ or $K$, while similar when $X$ was $R$. Based on similar $\Delta S^{\star}$ for mono- and di-basic peptide ions, let us suppose that only one basic residue interacts with the proton in TS. Then, the explanation for the above observation may have to be found from the reactant energy. $\mathrm{Wu}$ and Fenselau [21] observed large $G B$ values for peptides with two lysine residues and invoked stabilization of protonbound peptides by simultaneous interaction of the two residues with the proton. Similar stabilization may be responsible for larger $E_{0}$ for $\left[X Y_{4} X+\mathrm{H}\right]^{+}(X=H$ and $K)$ than those for their mono-basic counterparts. In the case of $\left[R Y_{4} R+\mathrm{H}\right]^{+}$, simultaneous interaction of two arginine residues with a proton may be ineffective due to sequestering of the proton by three nitrogen atoms in one residue. Accurate $P A$ or $G B$ data for the peptides studied in this work are needed to check such a possibility.

\section{Conclusion}

Product ion abundances in MALDI and PSD spectra of peptides have been found to decrease significantly in the presence of basic amino acid residues. This is in agreement with the charge-directed mechanism for the formation of $b$

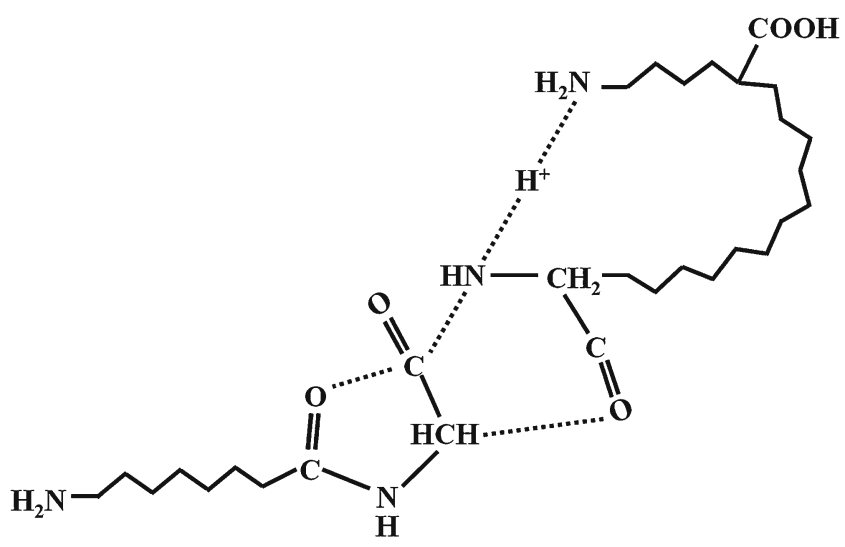

Figure 5. A proton-bound tricyclic transition structure in which a proton interacts both with the side chain of lysine at the C-terminus and with an amide backbone 
and $y$ ions in which migration of a proton to an amide backbone weakens the amide bond. Kinetic analysis of the data has shown that small change in dissociation kinetics is responsible for the observed basic residue effect. This indicates that the ionizing proton keeps interacting with a basic site even in the transition structure, which is compatible with highly negative critical entropy for peptide ion dissociation found in the previous and present kinetic studies.

The unified picture for the dissociation mechanism of peptide ions, which encompasses those without and with any basic residue, is a major outcome of the present study. It can be regarded as an improvement on the spectral correlation rule called 'mobile proton' model [1] that is very useful for interpreting tandem mass spectra of peptides.

\section{Acknowledgments}

The authors acknowledge financial support for this work by the National Research Foundation, Republic of Korea. S.H.Y. thanks the Ministry of Education, Science, and Technology, Republic of Korea, for Brain Korea 21 Fellowship.

\section{References}

1. Wysocki, V.H., Tsaprailis, G., Smith, L.L., Breci, L.A.: Mobile and localized protons: a framework for understanding peptide dissociation. J Mass Spectrom 35, 1399-1406 (2000)

2. Harrison, A.G.: To $b$ or not to $b$ : the ongoing saga of peptide $b$ ions. Mass Spectrom Rev 28, 640-654 (2009)

3. Polce, M.J., Ren, D., Wesdemiotis, C.: Dissociation of the peptide bond in protonated peptides. J Mass Spectrom 35, 1391-1398 (2000)

4. Paizs, B., Suhai, S.: Fragmentation pathways of protonated peptides. Mass Spectrom Rev 24, 508-548 (2005)

5. Biemann, K.: Sequencing of peptides by tandem mass spectrometry and high-energy collision-induced dissociation. In: McCloskey, J.A. (ed.) Methods in Enzymology, vol. CXCIII, Mass Spectrometry, pp. 455-479. Academic, New York (1990)

6. Aribi, H.E., Rodriquez, C.F., Almeida, D.R.P., Ling, Y., Mak, W.W.-N., Hopkinson, A.C., Siu, K.W.M.: Elucidation of fragmentation mechanisms of protonated peptide ions and their products: a case study on glycylglycylglycine using density functional theory and threshold collision-induced dissociation. J Am Chem Soc 125, 9229-9236 (2003)
7. Moon, J.H., Yoon, S.H., Kim, M.S.: Temperature of peptide ions generated by matrix-assisted laser desorption ionization and their dissociation kinetic parameters. J Phys Chem B 113, 2071-2076 (2009)

8. Yoon, S.H., Moon, J.H., Kim, M.S.: Time-resolved photodissociation study of singly protonated peptides with a histidine residue generated by matrix-assisted laser desorption ionization: dissociation rate constant and internal temperature. J Am Soc Mass Spectrom 20, 1522-1529 (2009)

9. Holbrook, K.A., Pilling, M.J., Robertson, S.H.: Unimolecular Reactions, pp. 39-78. Wiley, Chichester (1996)

10. Baer, T., Mayer, P.M.: Statistical Rice-Ramsperger-Kassel-Marcus quasi-equilibrium theory calculations in mass spectrometry. J Am Soc Mass Spectrom 8, 103-115 (1997)

11. Paizs, B., Suhai, S.: Combined quantum chemical and RRKM modeling of the main fragmentation pathways of protonated GGG. II. Formation $b_{2}, y_{1}$, and $y_{2}$ ions. Rapid Commun Mass Spectrom 16, 375-389 (2002)

12. Mowry, C.D., Johnston, M.V.: Internal energy of neutral molecules ejected by matrix-assisted laser desorption. J Phys Chem 98, 1904-1909 (1994)

13. Campbell, J.M., Vestal, M.L., Blank, P.S., Stein, S.E., Epstein, J.A., Yergey, A.L.: Fragmentation of leucine enkephalin as a function of laser fluence in a MALDI TOF-TOF. J Am Soc Mass Spectrom 18, 607-616 (2007)

14. Koubenakis, A., Frankevich, V., Zhang, J., Zenobi, R.: Time-resolved surface temperature measurement of MALDI matrices under pulsed UV laser irradiation. J Phys Chem A 108, 2405-2410 (2004)

15. Yoon, S.H., Moon, J.H., Kim, M.S.: A comparative study of in- and post-source decays of peptide and preformed ions in matrix-assisted laser desorption ionization time-of-flight mass spectrometry: effective temperature and matrix effect. J Am Soc Mass Spectrom 21, 1876-1883 (2010)

16. Gabelica, V., Schulz, E., Karas, M.: Internal energy build-up in matrixassisted laser desorption/ionization. J Mass Spectrom 39, 579-593 (2004)

17. Knochenmuss, R., Zhigilei, L.V.: Molecular dynamics simulations of MALDI: laser fluence and pulse width dependence of plume characteristics and consequences for matrix and analyte ionization. $J$ Mass Spectrom 45, 333-346 (2010)

18. Yoon, S.H., Kim, M.S.: Development of a time-resolved method for photodissociation mechanistic study of protonated peptides: use of a voltage-floated cell in a tandem time-of-flight mass spectrometer. $\mathrm{J} \mathrm{Am}$ Soc Mass Spectrom 18, 1729-1739 (2007)

19. Yoon, S.H., Moon, J.H., Choi, K.M., Kim, M.S.: A deflection system to reduce the interference from post-source decay product ions in photodissociation time-of-flight mass spectrometry. Rapid Commun Mass Spectrom 20, 2201-2208 (2006)

20. Harrison, A.G.: The gas-phase basicities and proton affinities of amino acids and peptides. Mass Spectrom. Rev 16, 201-217 (1997)

21. Wu, Z., Fenselau, C.: Structural determinants of gas phase basicities of peptides. Tetrahedron 49, 9197-9206 (1993) 